\title{
Circulating levels of 25-hydroxyvitamin D and risk of breast cancer: a nested case-control study
}

\author{
Stephanie Scarmo1', Yelena Afanasyeva ${ }^{1}$, Per Lenner ${ }^{2}$, Karen L Koenig ${ }^{1,3}$, Ronald L Horst ${ }^{4}$, Tess V Clendenen ${ }^{1}$, \\ Alan A Arslan ${ }^{1,3,5}$, Yu Chen ${ }^{1,3}$, Göran Hallmans ${ }^{6}$, Eva Lundin, Sabina Rinaldi ${ }^{8}$, Paolo Toniolo ${ }^{1,3,5}$, Roy E Shore ${ }^{1,9}$ and \\ Anne Zeleniuch-Jacquotte ${ }^{1,3^{*}}$
}

\begin{abstract}
Introduction: Experimental evidence suggests a protective role for circulating 25-hydroxyvitamin $\mathrm{D}(25(\mathrm{OH}) \mathrm{D})$ in breast cancer development, but the results of epidemiological studies have been inconsistent.

Methods: We conducted a case-control study nested within two prospective cohorts, the New York University Women's Health Study and the Northern Sweden Mammary Screening Cohort. Blood samples were collected at enrollment, and women were followed up for breast cancer ascertainment. In total, 1,585 incident breast cancer cases were individually-matched to 2,940 controls. Of these subjects, 678 cases and 1,208 controls contributed two repeat blood samples, at least one year apart. Circulating levels of $25(\mathrm{OH}) \mathrm{D}$ were measured, and multivariate odds ratios (ORs) and 95\% confidence intervals (Cls) were calculated using conditional logistic regression.
\end{abstract}

Results: No association was observed between circulating levels of $25(\mathrm{OH}) \mathrm{D}$ and overall breast cancer risk (multivariate-adjusted model $\mathrm{OR}=0.94,95 \% \mathrm{Cl}=0.76-1.16$ for the highest vs. lowest quintile, $p_{\text {trend }}=0.30$ ). The temporal reliability of 25(OH)D measured in repeat blood samples was high (intraclass correlation coefficients for season-adjusted $25(\mathrm{OH}) \mathrm{D}>0.70)$. An inverse association between $25(\mathrm{OH}) \mathrm{D}$ levels and breast cancer risk was observed among women who were $\leq 45$ years of age $\left(\mathrm{OR}_{\mathrm{Q} 5-\mathrm{Q} 1}=0.48,95 \% \mathrm{Cl}=0.30-0.79, p_{\text {trend }}=0.01\right)$ or premenopausal at enrollment $\left(\mathrm{OR}_{\mathrm{Q} 5-\mathrm{Q} 1}=0.67,95 \% \mathrm{Cl}=0.48-0.92, p_{\text {trend }}=0.03\right)$.

Conclusions: Circulating 25(OH)D levels were not associated with breast cancer risk overall, although we could not exclude the possibility of a protective effect in younger women. Recommendations regarding vitamin D supplementation should be based on considerations other than breast cancer prevention.

\section{Introduction}

Experimental studies support a role for vitamin D in reducing the risk of breast cancer [1,2]. Vitamin D, which is obtained from both dietary sources (food and supplements) and exposure to type $B$ ultraviolet radiation, undergoes two hydroxylation steps before becoming biologically active [3]. 25-hydroxyvitamin D [25(OH)D], produced in the liver from the first hydroxylation, is the precursor of the biologically active form, $1,25(\mathrm{OH})_{2} \mathrm{D}$, which is produced in the kidney as well as in target tissues, including the breast [4]. Circulating 25(OH)D is considered the best marker of vitamin D status because it reflects vitamin D

\footnotetext{
* Correspondence: anne.jacquotte@nyumc.org

'Department of Population Health, New York University School of Medicine, 650 First Avenue, New York, NY 10016, USA

Full list of author information is available at the end of the article
}

obtained from both diet/supplements and sun exposure [5] and has a longer half-life than $1,25(\mathrm{OH})_{2} \mathrm{D}$ [6]. Vitamin $\mathrm{D}$ acts by binding to the vitamin $\mathrm{D}$ receptor (VDR), which is expressed in mammary tissue. The VDR controls the expression of genes regulating cell proliferation, differentiation, and apoptosis $[1,7]$.

The results of epidemiologic studies examining the association between circulating 25(OH)D levels and breast cancer risk have been inconsistent. Seven prospective studies reported no association overall [8-14], whereas three reported a significant or marginally significant inverse association [15-17]. Some significant findings emerged from the results of subgroup analyses, although the subgroups of women for whom these associations were observed were not consistent across studies. The Nurses' Health Study observed a stronger protective effect of
Ciomed Central 
plasma 25(OH)D on breast cancer risk for women who were 60 years old or older [16], whereas the French E3N cohort observed a stronger effect in women who were less than 53 years old at enrollment [15]. In the Nurses' Health Study II, which consists primarily of pre-menopausal women, no association was observed overall between plasma $25(\mathrm{OH}) \mathrm{D}$ levels and breast cancer risk, and a positive, rather than an inverse, association was observed among women who were overweight or obese, the latter of which is defined as a body mass index (BMI) of at least $30 \mathrm{~kg} / \mathrm{m}^{2}$ [13].

Recent reviews have concluded that there is insufficient evidence to recommend vitamin D supplementation for the prevention of breast cancer but that additional research in humans is needed $[3,18,19]$. The purpose of our study was to examine the association between prediagnostic circulating levels of circulating 25(OH)D and breast cancer risk in a case-control study nested within two prospective cohorts: the New York University Women's Health Study (NYUWHS) and the Northern Sweden Mammary Screening Cohort (NSMSC). A unique feature of this study, the largest prospective study to date, was the availability of two $25(\mathrm{OH}) \mathrm{D}$ measurements from blood samples donated a minimum of one year apart for a large proportion of the study subjects, allowing us to estimate with good precision the temporal reliability of 25 $(\mathrm{OH}) \mathrm{D}$, and factors that affected it, in the two cohorts.

\section{Materials and methods Study population}

Descriptions of the NYUWHS and the NSMSC have been provided previously [20,21]. Briefly, the NYUWHS cohort enrolled 14,274 healthy women (34 to 65 years old) at a mammography screening clinic in New York City between 1985 and 1991, and the NSMSC enrolled, between 1995 and 2006, approximately 28,800 women (40 to 69 years old) who are participating in a population-based breast cancer screening program in Västerbotten County, Sweden. After written informed consent was obtained from all study participants, information on demographic and anthropometric variables, medical and reproductive history, family history of breast cancer, and lifestyle factors, including diet, was collected through baseline or subsequent questionnaires or both. Venous blood was collected at enrollment, processed according to standard procedures by the respective cohorts (serum for NYUWHS and plasma for NSMSC), and stored at $-80^{\circ} \mathrm{C}$. Additional blood samples were collected from women who returned for screening. This study was approved by the Institutional Review Board of the New York University School of Medicine, the Regional Ethics Committee of the University of Umeå, Sweden, and the Swedish Data Inspection Board.

\section{Case ascertainment and control selection}

For the NYUWHS, incident cases of invasive breast cancer were identified by mailed questionnaires or follow-up telephone interviews every 2 to 4 years after 1991, supplemented by linkages to state cancer registries in New York, New Jersey, and Florida and the US National Death Index. Medical records were reviewed to confirm self-reported cases. Using a capture-recapture analysis, we estimated that combining active and cancer registry-based follow-up resulted in a breast cancer ascertainment rate of 95\% [22]. For the NSMSC, annual linkages to the Swedish National Cancer Registry were used to identify incident cases of breast cancer in the cohort. As of 1 January 2007 for the NYUWHS and 1 January 2010 for the NSMSC, a total of 1,645 incident cases of invasive breast cancer (909 in the NYUWHS and 736 in the NSMSC) had been identified. In the NYUWHS, 16 cases (3\%) were excluded because they had a low serum balance. In the NSMSC, 44 cases (6\%) were excluded for the following reasons: 26 had low plasma balance, 13 had their plasma reserved because of a subsequent diagnosis of a rarer cancer or other disease, 3 had insufficient volume for laboratory measurement, and 2 had both matched controls excluded for one of the reasons above. The present study included a total of 1,585 incident breast cancer cases (893 from the NYUWHS and 692 from the NSMSC).

Each case was matched to two controls who were selected from the respective cohort by using incidencedensity sampling. Matching factors included age at enrollment in the study ( \pm 6 months), date of enrollment/first blood donation (NYUWHS: \pm 3 months; NSMSC: \pm 1 month), and number $(1,2+)$ and dates of subsequent blood donations. For the NYUWHS, matching factors also included menopausal status (pre- or postmenopausal) at enrollment and race/ethnicity (Caucasian, African-American, other, or unknown). The vast majority of women in the NSMSC were Caucasian. Initially, women were not matched on menopausal status in this cohort; however, $88 \%$ of the cases had at least one control matching on this factor (pre- and peri-menopausal combined or post-menopausal). In total, 2,940 controls were included in the final analysis (1,642 in NYUWHS and 1,298 in NSMSC).

For 678 matched sets (413 in NYUWHS and 265 in NSMSC), two blood samples were analyzed for 25(OH)D. For participants who had donated more than two blood samples, the first and last samples collected before the relevant case's diagnosis were selected.

\section{Laboratory methods}

Circulating 25(OH)D was measured by Heartland Assays, Inc. (Ames, IA, USA) by using a direct competitive chemiluminescence immunoassay by using the DiaSorin 
LIAISON platform (DiaSorin, Inc., Stillwater, MN, USA) [23]. The assay, which is appropriate for either serum or plasma, is co-specific for 25-hydroxyvitamin $\mathrm{D}_{3}$ and 25hydroxyvitamin $\mathrm{D}_{2}$. All samples, including repeat samples, from a case and her matched controls were analyzed together in the same laboratory batch to minimize laboratory variability. Laboratory personnel were blinded to case-control status of the study samples. Samples from quality-control pools ( $6 \%$ of total samples) were masked and inserted randomly in the batches. The intra- and inter-batch coefficients of variation (CVs) were $9.5 \%$ and $11.4 \%$, respectively, for NYUWHS and 7.4\% and 9.0\%, respectively, for NSMSC.

Estrone was measured by double-antibody radioimmunoassay with reagents from Diagnostic System Laboratories (Webster, TX, USA) at the Laboratory for Hormone Analyses at the International Agency for Research on Cancer, France, for post-menopausal women who were not using hormone replacement therapy (HRT). Intra- and inter-batch CVs were $6.7 \%$ and $12.6 \%$, respectively $[24,25]$.

\section{Statistical analysis}

We examined the temporal reliability of circulating $25(\mathrm{OH})$ D by using the intraclass correlation coefficient (ICC). In addition to calculating the overall ICC, we calculated ICCs according to time (years) between sample donations and according to season, for each cohort separately.

Conditional logistic regression was used to estimate odds ratios (ORs) and 95\% confidence intervals (CIs) for the associations of subject characteristics and circulating $25(\mathrm{OH}) \mathrm{D}$ with risk of breast cancer. We conducted analyses separately for each cohort as well as combining them. Because there was no evidence of cohort heterogeneity, most results are presented for the combined cohorts. $25(\mathrm{OH}) \mathrm{D}$ concentrations were $\log _{2}$-transformed to reduce departure from the normal distribution and were included in the model in one of three ways. First, we computed season-adjusted residuals to take into account the known variations of 25(OH)D with season [3]. For each 25(OH)D measurement, the residual was the difference between the observed $25(\mathrm{OH}) \mathrm{D}$ value and the value predicted for this day of the year, which was obtained by using a non-parametric local regression (Proc LOESS; SAS Institute Inc., Cary, NC, USA) with $25(\mathrm{OH}) \mathrm{D}$ as the dependent variable and day of the year of blood donation as the independent variable [26]. This regression model was run separately for each cohort by using all available $25(\mathrm{OH}) \mathrm{D}$ measurements (that is, including repeat samples). We conducted analyses by using cohort-specific season-adjusted quintiles based on the distribution of the residuals in controls. Second, we ran analyses with season-adjusted residuals on the continuous scale. All analyses based on residuals were conducted by using first (that is, baseline) samples only. Finally, we examined the association of circulating $25(\mathrm{OH}) \mathrm{D}$ with breast cancer risk by using pre-specified categories of 25 $(\mathrm{OH}) \mathrm{D}$ levels, which were defined by using cut-points recommended by the Institute of Medicine: less than 50 (inadequate), 50 to 74 (adequate), and at least $75 \mathrm{nmol} / \mathrm{L}$ (adequate to high) [3]. These analyses were conducted separately for 'winter' and 'summer', which were defined by examining the unadjusted 25(OH)D levels in controls within each cohort. Winter included the months of January to April, when mean levels were low (48.1 to $51.2 \mathrm{nmol} / \mathrm{L}$ ), and summer included the months of July to September, when mean levels were high $(62.0$ to $68.0 \mathrm{nmol} / \mathrm{L})$. There was little variation in mean level from month to month within each of these two seasons. Subjects who had measurements in both winter and summer were included in both season-specific analyses to increase the sample size. Because there was no difference in the main study findings between conditional logistic regression models and unconditional models adjusting for the matching factors and because using conditional regression resulted in the loss of matched sets with samples collected in different seasons for the case and her controls, unconditional logistic regression was used for the season-specific analyses. In analyses by quintiles and pre-specified categories, tests for trend were performed by using an ordered categorical variable. Tests for heterogeneity were carried out by comparing models that included interaction terms to models that excluded them or by using Cochran's Q statistic.

In each of the two cohorts, multivariate linear regression analyses were conducted among the controls to explore associations of potential confounders with 25 $(\mathrm{OH}) \mathrm{D}$. BMI was found to be a negative predictor of 25 $(\mathrm{OH}) \mathrm{D}$, whereas multivitamin supplement use and past use of HRT were positive predictors in both cohorts. Caucasian race and physical activity were also positive predictors of 25(OH)D in the NYUWHS, and alcohol consumption was a negative predictor in the NSMSC. Covariates in the final multivariate models included the following known breast cancer risk factors: age at menarche (continuous), age at first birth/parity (not more than 20,21 to 15,26 to 30 , more than 30 years, nulliparous), family history of breast cancer (no or yes), BMI (continuous), past HRT use (never or ever), and alcohol consumption. It is debatable whether to control for outdoor physical activity and multivitamin use, which have been associated with higher levels of circulating $25(\mathrm{OH}) \mathrm{D}[27,28]$ since these variables may influence breast cancer risk through their effect on $25(\mathrm{OH}) \mathrm{D}$ levels. However, these factors may affect breast cancer risk through other mechanisms [29], in which case they could act as possible confounders in analyses of $25(\mathrm{OH})$ $\mathrm{D}$ and breast cancer risk. Therefore, in addition to presenting models adjusting for the factors listed above, we 
present results adjusting for physical activity and multivitamin use (no or yes). In the NYUWHS, physical activity was expressed as metabolic equivalent of taskhours per week (MET-hours/week) from walking and vigorous exercise, and women were classified into tertiles. In the NSMSC, women were classified as inactive, moderately active, or active by combining data on physical activity at work and frequency of walking, biking, and exercising. Baseline data were used for all variables except HRT in the NYUWHS, which represented use up to the date of diagnosis (or index date for controls).

We performed multiple imputation by using fully conditional specification [30] for the following covariates with missing data: alcohol consumption (23\%), physical activity (23\%), multivitamin use (18\%), HRT use (6\%), age at menarche, parity, age at first full-term pregnancy, and BMI (all with not more than $2 \%$ missing data). We compared analyses including all subjects and imputed data for covariates to analyses including only subjects with no missing data (complete case method). Because results from both analyses were similar, we present only the analyses that included all subjects and imputed data.

We conducted stratified analyses by using conditional logistic regression for the following variables: age at enrollment, lag-time between blood donation and diagnosis, and estrogen receptor (ER) status. In order not to lose the matched sets in which a case and her controls were discordant, unconditional logistic regression, adjusted for cohort and age at blood sampling, was performed for the following variables: menopausal status, BMI, circulating estrone levels (for post-menopausal women only), and insulin-like growth factor 1 (IGF-I) levels. Tertiles were used for the IGF-1 analysis because of the limited number of women for whom IGF-1 had been measured (193 cases and 269 controls from the NYUWHS only). Finally, we performed an analysis limited to Caucasians ( $90 \%$ of subjects). All significance testing was two-sided, and a $P$ value of less than 0.05 was considered statistically significant.

\section{Results}

Descriptive statistics for the breast cancer cases and their matched controls are presented in Table 1. Mean age at enrollment was 54 years for both cases and controls. Cases were diagnosed an average of 8.7 years after blood donation. Established risk factors for breast cancer including younger age at menarche, nulliparity, older age at first full-term pregnancy, and having a first-degree family history of breast cancer - occurred more commonly in cases. Cases were more likely to report having used HRT. BMI was significantly different between cases and controls in post-menopausal women, among whom a greater proportion of cases were overweight and obese. Among the $77 \%$ of cases for which receptor status was known, $78 \%$ of tumors were ER-positive.
For women who donated more than one blood sample, the average time between sample donations was 2.1 years in the NYUWHS and 4.4 years in the NSMSC. Overall, the temporal reliability of $25(\mathrm{OH}) \mathrm{D}$ was good $(\mathrm{ICC}=0.65,95 \%$ CI 0.61 to 0.69 for NSMSC and $0.78,95 \%$ CI 0.76 to 0.80 for NYUWHS) and improved for NSMSC when seasonadjusted residuals were used $(\mathrm{ICC}=0.71,95 \% \mathrm{CI} 0.67$ to 0.74) (Table 2). The ICC for the NYUWHS was not changed by seasonal adjustment, because women in the NYUWHS generally returned to the screening center and donated a blood sample at the same time each year. We observed that the ICC decreased as time increased between sample donations, although this trend did not appear to extend beyond the first 8 years. For the NSMSC, the season-adjusted ICCs were 0.56 (95\% CI $=0.42$ to 0.68 ) for samples collected 5 to 8 years apart $(n=113$ subjects $)$ and $0.63(95 \% \mathrm{CI}=0.51$ to 0.74 ) for samples collected between 8 and 11.7 years apart ( $n=106$ subjects). For both cohorts, the ICC was substantially lower when one sample was donated in the winter and the other one in the summer months (ICC = $0.47,95 \% \mathrm{CI}=0.29$ to 0.61 for NSMSC, $n=92$; $\mathrm{ICC}=0.66$, $95 \% \mathrm{CI}=0.50$ to 0.77 for the NYUWHS, $n=68$ ).

Table 3 reports ORs and 95\% CIs for breast cancer risk according to season-adjusted quintiles of 25(OH)D. There was no association between circulating vitamin $\mathrm{D}$ and breast cancer risk overall (adjusted model $\mathrm{OR}_{\mathrm{Q} 5-\mathrm{Q} 1}=0.94$, $95 \% \mathrm{CI}=0.76$ to $1.16, P_{\text {trend }}=0.30$ ) or within either cohort. Results with $25(\mathrm{OH}) \mathrm{D}$ on the continuous scale were similar. Adjusting for physical activity and multivitamin use, in addition to the other confounders, did not materially affect the results $\left(\mathrm{OR}_{\mathrm{Q} 5-\mathrm{Q} 1}=0.94,95 \% \mathrm{CI}=\right.$ 0.76 to $1.16, P_{\text {trend }}=0.27$ ).

In analyses using pre-specified categories of circulating 25(OH)D (not adjusted for season), we observed no association with breast cancer risk for samples taken either in the winter, when more than half of the subjects had levels below $50 \mathrm{nmol} / \mathrm{L}$, or in the summer, when more of the subjects had levels more than $75 \mathrm{nmol} / \mathrm{L}$ (Table 4). A suggestive protective effect was observed for women in the NYUWHS who donated blood in the summer months $\left(\mathrm{OR}=0.69,95 \% \mathrm{CI}=0.45\right.$ to $1.07, P_{\text {trend }}=0.10$ for concentrations of at least 75 versus less than $50 \mathrm{nmol} / \mathrm{L}$ ), but no such association was observed in the NSMSC.

Table 5 shows the results of subgroup analyses. Higher circulating $25(\mathrm{OH}) \mathrm{D}$ was associated with a decreased risk of breast cancer among women who were pre-menopausal at blood donation $\left(\mathrm{OR}_{\mathrm{Q} 5-\mathrm{Q} 1}=0.67,95 \% \mathrm{CI}=0.48\right.$ to 0.92 , $\left.P_{\text {trend }}=0.03\right)$ but not among those who were post-menopausal $\left(\mathrm{OR}_{\mathrm{Q} 5-\mathrm{Q} 1}=1.21,95 \% \mathrm{CI}=0.92\right.$ to $1.58, P_{\text {trend }}=$ $\left.0.67, P_{\text {interaction }}=0.05\right)$. A similar protective effect was observed for women who were not more than 45 years old at blood donation $\left(\mathrm{OR}_{\mathrm{Q} 5-\mathrm{Q} 1}=0.48,95 \% \mathrm{CI}=0.30\right.$ to 0.79 , $\left.P_{\text {trend }}=0.01, P_{\text {interaction }}=0.08\right)$. There was no evidence of effect modification by ER status of the tumor, lag-time 
Table 1 Characteristics of breast cancer cases and matched controls

\begin{tabular}{|c|c|c|c|}
\hline Characteristic & $\begin{array}{c}\text { Case subjects } \\
\text { Number (percentage) }\end{array}$ & $\begin{array}{c}\text { Control subjects } \\
\text { Number (percentage) }\end{array}$ & $P$ value $^{\mathrm{a}}$ \\
\hline \multicolumn{4}{|l|}{ Age at enrollment, years } \\
\hline$\leq 45$ & $301(19 \%)$ & $575(20 \%)$ & \\
\hline $46-54$ & $557(35 \%)$ & $1,005(34 \%)$ & Matched \\
\hline$\geq 55$ & $727(46 \%)$ & $1,360(46 \%)$ & \\
\hline \multicolumn{4}{|l|}{ Age at diagnosis, years } \\
\hline$\leq 55$ & $393(25 \%)$ & & \\
\hline $56-64$ & $511(32 \%)$ & & \\
\hline$\geq 65$ & $681(43 \%)$ & & \\
\hline \multicolumn{4}{|l|}{ Race } \\
\hline Caucasian & $1,370(90 \%)$ & $2,484(90 \%)$ & \\
\hline African-American & $94(6 \%)$ & $163(6 \%)$ & Matched \\
\hline Other & $51(4 \%)$ & $118(4 \%)$ & \\
\hline Missing & 70 & 175 & \\
\hline \multicolumn{4}{|l|}{ Education } \\
\hline Some high school or less & $288(25 \%)$ & $582(26 \%)$ & \\
\hline Completed high school & $415(36 \%)$ & $820(37 \%)$ & 0.09 \\
\hline College or higher & $439(38 \%)$ & $801(36 \%)$ & \\
\hline Missing & 443 & 737 & \\
\hline \multicolumn{4}{|l|}{ Menopausal status at enrollment } \\
\hline Pre- or peri-menopausal & $637(40 \%)$ & $1,134(39 \%)$ & Matched $^{\mathrm{b}}$ \\
\hline Post-menopausal & $948(60 \%)$ & $1,806(61 \%)$ & \\
\hline \multicolumn{4}{|l|}{ Age at menarche, years } \\
\hline$<12$ & $285(18 \%)$ & $477(17 \%)$ & \\
\hline 12 & $397(26 \%)$ & $670(23 \%)$ & \\
\hline 13 & $439(28 \%)$ & $803(28 \%)$ & 0.005 \\
\hline$>13$ & $438(28 \%)$ & $926(32 \%)$ & \\
\hline Missing & 26 & 64 & \\
\hline Nulliparous & $327(21 \%)$ & $530(18 \%)$ & 0.029 \\
\hline Missing & 46 & 63 & \\
\hline \multicolumn{4}{|l|}{$\begin{array}{l}\text { Age at first full-term pregnancy, } \\
\text { years }\end{array}$} \\
\hline$\leq 20$ & $171(14 \%)$ & 409 (18\%) & \\
\hline $21-25$ & $523(44 \%)$ & $1,016(44 \%)$ & \\
\hline $26-30$ & $318(27 \%)$ & $596(26 \%)$ & 0.006 \\
\hline$>30$ & $172(15 \%)$ & $281(12 \%)$ & \\
\hline Missing & 28 & 45 & \\
\hline Ever user of oral contraceptives & $677(46 \%)$ & $1219(45 \%)$ & 0.45 \\
\hline Missing & 121 & 209 & \\
\hline $\begin{array}{l}\text { Ever user of hormone } \\
\text { replacement therapy }\end{array}$ & $445(30 \%)$ & $685(25 \%)$ & $<0.001$ \\
\hline Missing & 99 & 176 & \\
\hline $\begin{array}{l}\text { First-degree family history of } \\
\text { breast cancer }\end{array}$ & 299 (19\%) & $437(15 \%)$ & 0.0005 \\
\hline \multicolumn{4}{|l|}{ Body mass index, $\mathrm{kg} / \mathrm{m}^{2}$} \\
\hline \multicolumn{4}{|l|}{ Pre- and peri-menopausal } \\
\hline$<20.0$ & $53(8 \%)$ & $104(9 \%)$ & \\
\hline $20.0-24.9$ & $339(54 \%)$ & $614(55 \%)$ & 0.24 \\
\hline$\geq 25.0$ & $237(38 \%)$ & $409(36 \%)$ & \\
\hline Missing & 8 & 7 & \\
\hline \multicolumn{4}{|l|}{ Post-menopausal } \\
\hline$<20.0$ & $31(3 \%)$ & $78(4 \%)$ & \\
\hline $20.0-24.9$ & 396 (43\%) & 848 (48\%) & \\
\hline
\end{tabular}


Table 1 Characteristics of breast cancer cases and matched controls (Continued)

\begin{tabular}{|c|c|c|c|}
\hline$\geq 25.0$ & 498 (54\%) & $835(48 \%)$ & 0.0009 \\
\hline Missing & 23 & 45 & \\
\hline Multivitamin user & $515(41 \%)$ & $956(39 \%)$ & 0.49 \\
\hline Missing & 332 & 509 & \\
\hline Ever smoker & $642(50 \%)$ & $1,264(52 \%)$ & 0.52 \\
\hline Missing & 299 & 524 & \\
\hline \multicolumn{4}{|l|}{ Alcohol, drinks per day } \\
\hline 0 & $501(43 \%)$ & $928(41 \%)$ & \\
\hline$<1$ & $552(47 \%)$ & 1,161 (51\%) & \\
\hline$\geq 1$ & $123(10 \%)$ & $187(8 \%)$ & 0.80 \\
\hline Missing & 409 & 664 & \\
\hline \multicolumn{4}{|l|}{ Physical activity } \\
\hline \multicolumn{4}{|l|}{$\begin{array}{l}\text { NYUWHS, MET-hours per } \\
\text { week }\end{array}$} \\
\hline$<5.5$ & $249(31 \%)$ & $412(28 \%)$ & \\
\hline $5.5-21.5$ & $271(34 \%)$ & $506(35 \%)$ & 0.12 \\
\hline$\geq 21.5$ & $274(35 \%)$ & $548(37 \%)$ & \\
\hline Missing & 99 & 176 & \\
\hline \multicolumn{4}{|l|}{$\begin{array}{l}\text { Mammary Screening Cohort, } \\
\text { activity level }\end{array}$} \\
\hline Inactive & $55(14 \%)$ & 107 (13\%) & \\
\hline Moderately active & 145 (37\%) & $305(37 \%)$ & \\
\hline Active & 192 (49\%) & $408(50 \%)$ & 0.84 \\
\hline Missing & 300 & 478 & \\
\hline $\begin{array}{l}\text { Dietary vitamin D in IU/day, } \\
\text { median (10th-90th percentile) }\end{array}$ & $141(55,272)$ & $145(55,275)$ & 0.60 \\
\hline Missing & 340 & 526 & \\
\hline $\begin{array}{l}\text { Circulating } 25(\mathrm{OH}) \mathrm{D} \text { in } \mathrm{nmol} / \mathrm{L} \text {, } \\
\text { median (10-90th percentile) }\end{array}$ & $53.0(31.2,81.0)$ & $54.2(30.7,82.6)$ & 0.27 \\
\hline
\end{tabular}

${ }^{\mathrm{a}} P$ value from conditional logistic regression ( $P$ value from trend test for ordered categories). ${ }^{\mathrm{b}}$ Menopausal status (pre- or post-menopausal) was a matching factor for all sets in the New York University Women's Health Study (NYUWHS). For Northern Sweden Mammary Screening Cohort (NSMSC), women were not initially matched on this factor, and $88 \%$ of the cases had at least one control matched on menopausal status (pre- and peri-menopausal combined or postmenopausal). 25(OH)D, 25-hydroxyvitamin D; MET, metabolic equivalent of task.

Table 2 Intraclass correlation coefficients by time between sample donation (years) and by season (NSMSC and NYUWHS)

\begin{tabular}{|c|c|c|c|c|}
\hline & \multicolumn{2}{|c|}{ NSMSC } & \multicolumn{2}{|c|}{ NYUWHS } \\
\hline & Number of subjects & ICC (95\% Cl) & Number of subjects & ICC (95\% Cl) \\
\hline$\overline{\mathrm{All}^{\mathrm{a}}}$ & 700 & $0.65(0.61,0.69)$ & 1,168 & $0.78(0.76,0.80)$ \\
\hline$A \|^{\mathrm{b}}$ & 700 & $0.71(0.67,0.74)$ & 1,168 & $0.78(0.76,0.80)$ \\
\hline \multicolumn{5}{|l|}{ Time between samples ${ }^{\mathrm{b}}$, years } \\
\hline$\leq 1$ & & & 393 & $0.80(0.76,0.83)$ \\
\hline$>1-2$ & 146 & $0.79(0.71,0.84)$ & 325 & $0.81(0.77,0.84)$ \\
\hline$>2-3$ & 139 & $0.81(0.75,0.86)$ & 208 & $0.80(0.75,0.84)$ \\
\hline$>3-5$ & 196 & $0.71(0.63,0.73)$ & 214 & $0.74(0.67,0.79)$ \\
\hline$>5-8$ & 113 & $0.56(0.42,0.68)$ & & \\
\hline$>8-11.7$ & 106 & $0.63(0.51,0.74)$ & & \\
\hline \multicolumn{5}{|l|}{ Seasons ${ }^{\mathrm{a}}$} \\
\hline Both samples in winter & 148 & $0.74(0.66,0.81)$ & 266 & $0.78(0.72,0.82)$ \\
\hline Both samples in summer & 53 & $0.79(0.67,0.88)$ & 210 & $0.81(0.76,0.85)$ \\
\hline One sample in winter, one in summer & 92 & $0.47(0.29,0.61)$ & 68 & $0.66(0.50,0.77)$ \\
\hline
\end{tabular}

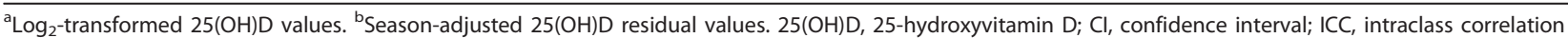
coefficient; NSMSC, Northern Sweden Mammary Screening Cohort; NYUWHS, New York University Women's Health Study. 
Table 3 Odds ratios and $95 \%$ confidence intervals for breast cancer risk according to season-adjusted circulating levels of $25(\mathrm{OH}) \mathrm{D}$ (by quintiles and as a continuous variable)

\begin{tabular}{|c|c|c|c|c|c|c|c|c|}
\hline & \multicolumn{6}{|c|}{ Quintiles } & \multicolumn{2}{|c|}{ Continuous } \\
\hline & 1 & 2 & 3 & 4 & 5 & $P_{\text {trend }}$ & OR $(95 \% \mathrm{Cl})^{\mathrm{a}}$ & $P$ value \\
\hline \multicolumn{9}{|l|}{ Both cohorts } \\
\hline Cases/controls & $311 / 589$ & $362 / 588$ & $309 / 588$ & $315 / 588$ & $288 / 587$ & & & \\
\hline Unadjusted model & 1.0 (ref) & $1.18(0.97,1.43)$ & $0.99(0.81,1.21)$ & $1.02(0.84,1.24)$ & $0.93(0.76,1.14)$ & 0.18 & $0.94(0.84,1.06)$ & 0.31 \\
\hline Adjusted model $^{b}$ & 1.0 (ref) & $1.16(0.95,1.42)$ & $1.00(0.81,1.22)$ & $1.04(0.85,1.27)$ & $0.94(0.76,1.16)$ & 0.30 & $0.95(0.84,1.08)$ & 0.44 \\
\hline Adjusted model $^{c}$ & 1.0 (ref) & $1.16(0.95,1.42)$ & $0.99(0.81,1.21)$ & $1.03(0.84,1.27)$ & $0.94(0.76,1.16)$ & 0.27 & $0.95(0.84,1.07)$ & 0.40 \\
\hline \multicolumn{9}{|l|}{ NYUWHS } \\
\hline Cases/controls & $191 / 329$ & $190 / 328$ & $176 / 329$ & $170 / 328$ & $166 / 328$ & & & \\
\hline Unadjusted model & 1.0 (ref) & $0.99(0.76,1.29)$ & $0.92(0.71,1.20)$ & $0.89(0.69,1.16)$ & $0.86(0.66,1.12)$ & 0.18 & $0.91(0.79,1.05)$ & 0.21 \\
\hline Adjusted model $^{b}$ & 1.0 (ref) & $0.98(0.75,1.28)$ & $0.94(0.72,1.23)$ & $0.92(0.70,1.21)$ & $0.88(0.67,1.16)$ & 0.31 & $0.93(0.80,1.08)$ & 0.34 \\
\hline Adjusted model $^{c}$ & 1.0 (ref) & $1.00(0.76,1.31)$ & $0.95(0.73,1.24)$ & $0.93(0.71,1.22)$ & $0.90(0.68,1.19)$ & 0.37 & $0.94(0.81,1.09)$ & 0.42 \\
\hline \multicolumn{9}{|l|}{ NSMSC } \\
\hline Cases/controls & $120 / 260$ & $172 / 260$ & $133 / 259$ & $145 / 260$ & $122 / 259$ & & & \\
\hline Unadjusted model & 1.0 (ref) & $1.47(1.09,1.97)$ & $1.10(0.81,1.49)$ & $1.22(0.90,1.64)$ & $1.03(0.75,1.40)$ & 0.62 & $1.00(0.82,1.23)$ & 0.99 \\
\hline Adjusted model $^{b}$ & 1.0 (ref) & $1.48(1.08,2.01)$ & $1.09(0.79,1.49)$ & $1.26(0.92,1.72)$ & $1.05(0.76,1.46)$ & 0.74 & $1.02(0.82,1.26)$ & 0.89 \\
\hline Adjusted model $^{c}$ & 1.0 (ref) & $1.46(1.07,1.99)$ & $1.08(0.79,1.48)$ & $1.24(0.91,1.70)$ & $1.04(0.75,1.45)$ & 0.71 & $1.01(0.81,1.26)$ & 0.94 \\
\hline
\end{tabular}

${ }^{a}$ Odds ratio (OR) for a doubling in 25(OH)D level. ${ }^{b}$ Adjusted for age at menarche (continuous), age at first birth/parity ( $\leq 20,21-25,26-30,>30$ years, nulliparous), family history of breast cancer (no or yes), body mass index (continuous), hormone replacement therapy use (never or ever), and alcohol consumption (continuous). 'Adjusted for physical activity and multivitamin use in addition to variables in footnote a. 25(OH)D, 25-hydroxyvitamin D; Cl, confidence interval; NSMSC, Northern Sweden Mammary Screening Cohort; NYUWHS, New York University Women's Health Study; ref, reference.

Table 4 Odds ratios and $95 \%$ confidence intervals for breast cancer risk according to pre-specified categories of circulating 25(OH)D concentration by season ${ }^{a}$

\begin{tabular}{|c|c|c|c|c|c|c|c|}
\hline & & \multicolumn{4}{|c|}{ Pre-specified categories, $\mathrm{nmol} / \mathrm{L}$} & \multirow[t]{2}{*}{ Continuous $^{\mathrm{b}}$} & \multirow[t]{2}{*}{$P$ value } \\
\hline & & $<50$ & $50-74$ & $75+$ & $P_{\text {trend }}$ & & \\
\hline \multicolumn{8}{|c|}{ Winter (Jan., Feb., March, April) } \\
\hline \multirow[t]{2}{*}{ Both cohorts ${ }^{c}$} & Cases/controls & $391 / 704$ & $244 / 472$ & $65 / 116$ & & & \\
\hline & OR $(95 \% \mathrm{Cl})$ & 1.0 (ref) & $0.94(0.77,1.15)$ & $1.06(0.76,1.48)$ & 0.95 & $0.97(0.82,1.15)$ & 0.74 \\
\hline \multirow[t]{2}{*}{ NYUWHS } & Cases/controls & $193 / 331$ & $105 / 217$ & $35 / 65$ & & & \\
\hline & OR $(95 \% \mathrm{Cl})$ & 1.0 (ref) & $0.82(0.61,1.10)$ & $0.91(0.58,1.44)$ & 0.35 & $0.90(0.73,1.13)$ & 0.37 \\
\hline \multirow[t]{2}{*}{ NSMSC } & Cases/controls & 198/373 & $139 / 255$ & $30 / 51$ & & & \\
\hline & OR $(95 \% \mathrm{Cl})$ & 1.0 (ref) & $1.10(0.83,1.46)$ & $1.25(0.76,2.06)$ & 0.34 & $1.11(0.85,1.47)$ & 0.44 \\
\hline \multicolumn{8}{|c|}{ Summer (July, Aug., Sept.) } \\
\hline \multirow[t]{2}{*}{ Both cohorts ${ }^{c}$} & Cases/controls & $113 / 186$ & $217 / 348$ & $99 / 212$ & & & \\
\hline & OR $(95 \% \mathrm{Cl})$ & 1.0 (ref) & $1.02(0.75,1.38)$ & $0.76(0.53,1.09)$ & 0.14 & $0.82(0.64,1.05)$ & 0.12 \\
\hline \multirow[t]{2}{*}{ NYUWHS } & Cases/controls & $77 / 121$ & $125 / 190$ & $67 / 148$ & & & \\
\hline & OR $(95 \% \mathrm{Cl})$ & 1.0 (ref) & $1.07(0.73,1.56)$ & $0.69(0.45,1.07)$ & 0.10 & $0.80(0.60,1.07)$ & 0.14 \\
\hline \multirow[t]{2}{*}{ NSMSC } & Cases/controls & $36 / 65$ & $92 / 158$ & $32 / 64$ & & & \\
\hline & $\mathrm{R}(95 \% \mathrm{Cl})$ & 1.0 (ref) & $0.99(0.59,1.67)$ & $0.89(0.46,1.70)$ & 0.72 & $0.88(0.52,1.47)$ & 0.61 \\
\hline
\end{tabular}

${ }^{\mathrm{a}}$ Adjusted for age at menarche (continuous), family history of breast cancer (no or yes), age at first birth/parity ( $\leq 20,21-25,26-30,>30$ years, nulliparous), body mass index (continuous), hormone replacement therapy use (never or ever), and alcohol consumption (continuous). ${ }^{b}$ Odds ratio (OR) for a doubling in $25(\mathrm{OH}) \mathrm{D}$ level. 'Adjusted for cohort in addition to all factors in footnote a. 25(OH)D, 25-hydroxyvitamin D; Cl, confidence interval; NSMSC, Northern Sweden Mammary Screening Cohort; NYUWHS, New York University Women's Health Study; ref, reference.

between blood sampling and diagnosis, BMI, or circulating estrone levels. Results of the analysis limited to Caucasians were similar to those of the analysis that included all subjects.

When we examined the association of $25(\mathrm{OH}) \mathrm{D}$ with breast cancer risk by IGF-1 levels at baseline, the ORs for the third tertile were $0.62(95 \% \mathrm{CI}=0.30$ to 1.28$)$ in the below-median stratum and 0.79 (95\% CI $=0.39$ to 1.62$)$ in the above-median stratum. The test for interaction between IGF-1 and $25(\mathrm{OH}) \mathrm{D}$ on the continuous scale was not statistically significant $(P=0.61)$. 
Table 5 Stratified odds ratios and $95 \%$ confidence intervals for breast cancer risk according to quintiles of seasonadjusted residual values of circulating $25(\mathrm{OH}) \mathrm{D}$ concentration at enrollment

\begin{tabular}{|c|c|c|c|c|c|c|c|c|}
\hline & & \multicolumn{7}{|c|}{ Quintiles } \\
\hline & & 1 & 2 & 3 & 4 & 5 & $P_{\text {trend }}$ & $P_{\text {het }}{ }^{\mathrm{a}}$ \\
\hline \multicolumn{9}{|l|}{ Caucasians $^{\mathrm{b}}$} \\
\hline & Cases/controls & 209/399 & 298/449 & $270 / 469$ & $282 / 473$ & $244 / 471$ & 0.46 & 0.31 \\
\hline & OR $(95 \% \mathrm{Cl})$ & 1.00 & $1.28(1.01,1.62)$ & $1.10(0.87,1.38)$ & $1.17(0.92,1.48)$ & $0.97(0.76,1.24)$ & & \\
\hline \multicolumn{9}{|c|}{ Age at enrollment, years ${ }^{\mathrm{b}}$} \\
\hline \multirow[t]{2}{*}{$\leq 45$} & Cases/controls & $72 / 101$ & $54 / 103$ & $62 / 103$ & $61 / 110$ & $52 / 136$ & & \\
\hline & OR $(95 \% \mathrm{Cl})$ & 1.00 & $0.67(0.42,1.07)$ & $0.78(0.49,1.25)$ & $0.73(0.46,1.14)$ & $0.48(0.30,0.79)$ & 0.01 & 0.08 \\
\hline \multirow[t]{2}{*}{$45-54$} & Cases/controls & $118 / 220$ & $116 / 220$ & $97 / 201$ & $117 / 209$ & 109/186 & & \\
\hline & OR $(95 \% \mathrm{Cl})$ & 1.00 & $0.92(0.65,1.29)$ & $0.82(0.58,1.17)$ & $0.99(0.70,1.40)$ & $1.04(0.73,1.48)$ & 0.73 & \\
\hline \multirow[t]{2}{*}{$\geq 55$} & Cases/controls & $121 / 268$ & $192 / 265$ & $150 / 284$ & $137 / 269$ & $127 / 265$ & & \\
\hline & OR $(95 \% \mathrm{Cl})$ & 1.00 & $1.76(1.30,2.38)$ & $1.28(0.94,1.73)$ & $1.28(0.94,1.75)$ & $1.20(0.87,1.66)$ & 0.96 & \\
\hline \multicolumn{9}{|l|}{ Lag-time to diagnosis $^{\mathrm{b}}$} \\
\hline \multirow[t]{2}{*}{$\leq 8$ years } & Cases/controls & $123 / 261$ & $174 / 240$ & $144 / 258$ & $140 / 253$ & $141 / 252$ & & \\
\hline & OR $(95 \% \mathrm{Cl})$ & 1.00 & $1.62(1.19,2.22)$ & $1.23(0.90,1.69)$ & $1.26(0.92,1.73)$ & $1.18(0.85,1.63)$ & 0.99 & 0.30 \\
\hline \multirow[t]{2}{*}{$>8$ years } & Cases/controls & $188 / 328$ & $188 / 348$ & $165 / 330$ & $175 / 335$ & $157 / 335$ & & \\
\hline & OR $(95 \% \mathrm{Cl})$ & 1.00 & $0.92(0.71,1.20)$ & $0.86(0.66,1.13)$ & $0.91(0.70,1.19)$ & $0.82(0.62,1.08)$ & 0.20 & \\
\hline \multicolumn{9}{|l|}{$\overline{\text { ER status }^{\mathrm{b}}}$} \\
\hline \multirow[t]{2}{*}{$\mathrm{ER}^{+}$} & Cases/controls & $173 / 355$ & 219/347 & $178 / 358$ & $200 / 355$ & $78 / 352$ & & \\
\hline & OR $(95 \% \mathrm{Cl})$ & 1.00 & $1.31(1.00,1.70)$ & $1.04(0.80,1.35)$ & $1.22(0.93,1.58)$ & $1.10(0.83,1.44)$ & 0.79 & 0.79 \\
\hline \multirow[t]{2}{*}{$E R^{-}$} & Cases/controls & $53 / 99$ & $60 / 99$ & $56 / 111$ & 49/93 & $54 / 95$ & & \\
\hline & OR $(95 \% \mathrm{Cl})$ & 1.00 & $1.03(0.63,1.70)$ & $0.99(0.60,1.64)$ & $1.00(0.61,1.66)$ & $1.08(0.64,1.85)$ & 0.85 & \\
\hline \multicolumn{9}{|l|}{ Menopausal status $^{c}$} \\
\hline \multirow[t]{2}{*}{ Pre-menopausal } & Cases/controls & $150 / 229$ & $128 / 228$ & $122 / 218$ & $123 / 221$ & $114 / 238$ & & \\
\hline & OR $(95 \% \mathrm{Cl})$ & 1.00 & $0.80(0.59,1.09)$ & $0.79(0.58,1.08)$ & $0.80(0.58,1.09)$ & $0.67(0.48,0.92)$ & 0.03 & 0.05 \\
\hline \multirow[t]{2}{*}{ Post-menopausal } & Cases/controls & $161 / 360$ & $234 / 360$ & $187 / 370$ & $192 / 367$ & $174 / 349$ & & \\
\hline & OR $(95 \% \mathrm{Cl})$ & 1.00 & $1.48(1.15,1.90)$ & $1.16(0.89,1.50)$ & $1.22(0.94,1.58)$ & $1.21(0.92,1.58)$ & 0.67 & \\
\hline \multicolumn{9}{|l|}{$\overline{B M l^{c}, k g / m^{2}}$} \\
\hline \multirow[t]{2}{*}{$<25$} & Cases/controls & $115 / 245$ & $153 / 312$ & $164 / 323$ & 195/361 & 192/403 & & \\
\hline & OR $(95 \% \mathrm{Cl})$ & 1.00 & $1.01(0.75,1.36)$ & $1.05(0.78,1.40)$ & $1.10(0.83,1.47)$ & $0.97(0.73,1.29)$ & 0.99 & 0.56 \\
\hline \multirow[t]{2}{*}{$25+$} & Cases/controls & 187/331 & $201 / 267$ & $142 / 260$ & $115 / 215$ & $90 / 171$ & & \\
\hline & OR $(95 \% \mathrm{Cl})$ & 1.00 & $1.31(1.01,1.70)$ & $0.93(0.70,1.22)$ & $0.91(0.68,1.22)$ & $0.93(0.68,1.27)$ & 0.16 & \\
\hline \multicolumn{9}{|l|}{ Estrone, $\mathrm{pg} / \mathrm{mL}^{\mathrm{c}, \mathrm{d}}$} \\
\hline \multirow[t]{2}{*}{$<23.25$} & Cases/controls & $32 / 90$ & $42 / 85$ & $40 / 94$ & $44 / 97$ & $33 / 102$ & & \\
\hline & OR $(95 \% \mathrm{Cl})$ & 1.00 & $1.38(0.79,2.41)$ & $1.19(0.68,2.09)$ & $1.36(0.78,2.36)$ & $0.95(0.53,1.70)$ & 0.83 & 0.41 \\
\hline \multirow[t]{2}{*}{$23.25-32.45$} & Cases/controls & $43 / 83$ & $59 / 82$ & $48 / 91$ & $53 / 81$ & $47 / 74$ & & \\
\hline & OR $(95 \% \mathrm{Cl})$ & 1.00 & $1.40(0.84,2.33)$ & $1.03(0.61,1.73)$ & $1.33(0.78,2.25)$ & $1.29(0.75,2.22)$ & 0.49 & \\
\hline \multirow[t]{2}{*}{$>32.45$} & Cases/controls & $48 / 83$ & $80 / 94$ & $56 / 80$ & $37 / 82$ & $41 / 52$ & & \\
\hline & OR $(95 \% \mathrm{Cl})$ & 1.00 & $1.70(1.05,2.76)$ & $1.36(0.81,2.27)$ & $0.87(0.50,1.50)$ & $1.66(0.94,2.95)$ & 0.82 & \\
\hline
\end{tabular}

${ }^{\mathrm{a}}$ Cochran's Q statistic was used to test for heterogeneity according to lag-time and estrogen receptor (ER) status. ${ }^{\mathrm{b}}$ Adjusted for age at menarche (continuous), family history of breast cancer (yes or no), age at first birth/parity ( $\leq 20,21-25,26-30,>30$ years, nulliparous), body mass index (BMI) (continuous), hormone replacement therapy use (ever or never), and alcohol consumption (continuous). 'Unconditional logistic regression analyses adjusted for cohort and age at sampling in addition to all factors in footnote b. ${ }^{d}$ Measured in post-menopausal women only. 25(OH)D, 25-hydroxyvitamin D; Cl, confidence interval; OR, odds ratio.

\section{Discussion}

In this case-control study nested within two cohorts, we did not observe an association between circulating $25(\mathrm{OH})$ $\mathrm{D}$ and breast cancer risk overall. We observed an inverse association between $25(\mathrm{OH}) \mathrm{D}$ and breast cancer risk in the subgroups of women who were not more than 45 years old or pre-menopausal at blood donation, although the test for interaction was significant only for menopausal status. Because of substantial overlap, we were not able to sort out whether younger age or pre-menopausal status was driving the association.

Epidemiologic studies on vitamin D and breast cancer risk have been reviewed recently [31,32]. Traditional case-control studies [33-39] with blood samples collected 
after breast cancer diagnosis have found inverse associations between circulating 25(OH)D and breast cancer risk. However, changes in lifestyle, particularly physical activity, following breast cancer diagnosis and treatment may affect circulating $25(\mathrm{OH}) \mathrm{D}$, and associations observed in these studies therefore may not reflect prediagnosis associations [32]. Among the 10 prospective studies published to date, eight reported no association overall [8-14], one reported a marginally significant inverse association [16], and one reported a significant inverse association [15].

In regard to younger and pre-menopausal women, data from prospective studies are more limited since eligibility in some of the largest studies was restricted to older women [8-10]. Among the five prospective studies that reported results in younger or pre-menopausal women or both, four reported no association [11-13,16]. In the largest of the four studies, the Nurses' Health Study II, which collected blood in relatively young (age range of 32 to 54 years), mostly pre-menopausal women, a large number of whom were still pre-menopausal at diagnosis (294 cases), the multivariate-adjusted OR associated with the top quintile of $25(\mathrm{OH}) \mathrm{D}$ was $1.19\left(95 \% \mathrm{CI}=0.77\right.$ to $\left.1.84, P_{\text {trend }}=0.51\right)$. The French E3N cohort, though, reported a significant inverse association in women who were younger $(<53$ years old) at blood donation, results consistent with ours, and also observed a non-significant protective association in the smaller subgroup of women who were pre-menopausal at diagnosis. The investigators suggested that vitamin D may act by inhibiting the tumor growth-stimulating effects of IGF-1 [15]. Because IGF-1 levels decrease with age, a stronger anticarcinogenic effect of vitamin $D$ would be expected in younger/pre-menopausal women. However, our analysis stratifying directly by IGF-1 level did not support this hypothesis, although the sample size was limited.

A protective effect of vitamin $\mathrm{D}$ on breast cancer would also be expected to be stronger in pre-menopausal women if vitamin $\mathrm{D}$ acts by inhibiting estrogen-stimulated breast cell proliferation [40], since estrogen levels are much higher before menopause. However, we found no evidence that the effect of vitamin $D$ varies according to estrone levels in post-menopausal women, in spite of the strong positive association between estrone and breast cancer risk in our study. Moreover, $25(\mathrm{OH}) \mathrm{D}$ was not associated with either ER-positive or ER-negative breast cancer, and this is consistent with results from other prospective studies of $25(\mathrm{OH}) \mathrm{D}$ that found no difference by ER status $[10,13]$.

Too few subjects had very high concentrations of 25 $(\mathrm{OH}) \mathrm{D}$ for us to be able to examine the association of concentrations of at least $100 \mathrm{nmol} / \mathrm{L}$ with breast cancer risk. However, the lack of dose response in the less than
50 to at least $75 \mathrm{nmol} / \mathrm{L}$ range (Table 4) suggests that a true association would have to be of the threshold type, a hypothesis for which there is little biological support. A linear dose-response association at levels of not more than $75 \mathrm{nmol} / \mathrm{L}$ has been observed for colorectal cancer, the one type of cancer for which there is consistent evidence of a protective effect of vitamin D [41].

Several factors that are associated with breast cancer risk are also associated with circulating 25(OH)D and therefore could confound the $25(\mathrm{OH}) \mathrm{D}$-breast cancer association [42]. Dark skin, higher BMI, and lower physical activity have been repeatedly found to be associated with lower levels of $25(\mathrm{OH}) \mathrm{D}$, whereas associations between $25(\mathrm{OH}) \mathrm{D}$ and current use of HRT, vitamin supplements, and alcohol have been less consistent $[28,42,43]$. The importance of taking into account these lifestyle factors was demonstrated in the Women's Health Initiative study, in which a significant inverse association of $25(\mathrm{OH}) \mathrm{D}$ with breast cancer risk was attenuated and became non-significant after adjustment for BMI and physical activity [42]. In our study, we matched on race/ethnicity (a surrogate for dark skin) and also conducted analyses limited to Caucasians, and this gave results similar to the analyses that included all races. As shown in Tables 3, 4, and 5, adjusting for BMI, HRT use, physical activity, and multivitamin use had very little effect on the ORs. Residual confounding is possible, particularly by physical activity, for which we classified women in one of three categories and data were missing for $11 \%$ in the NYUWHS and $38 \%$ in the NSMSC. However, an analysis limited to the subjects for whom physical activity was available showed very similar results, as did an analysis adjusting for MET-hours per week as a continuous variable in the NYUWHS (data not shown). Another potential source of confounding is breast cancer screening frequency, as screening visits that are more frequent could result in earlier diagnosis of breast cancer or correlate with other health-conscious behaviors leading to higher $25(\mathrm{OH}) \mathrm{D}$ status. However, because blood donations occurred at the time of mammographic screening visits, number of blood donations can be considered a proxy for mammographic screening frequency. We matched on number of blood donations in the NYUWHS, whereas in the NSMSC, although we did not match on this variable, $59 \%$ of cases had at least one control who matched exactly on the number of blood donations, and $89 \%$ of cases had at least one control who matched within \pm 1 blood donation. We therefore believe that confounding by screening history is unlikely in our study.

We used residuals obtained by local regression to take into account seasonal variation. This method has been used only rarely in studies of $25(\mathrm{OH}) \mathrm{D}$ [44], although it has been used in epidemiologic analyses of other 
biomarkers with temporal variation (for instance, hormones known to vary during pregnancy) $[45,46]$. In our study, when the residual method was used, the exposure value for each woman was the difference between the absolute level observed for this woman and the projected mean of $25(\mathrm{OH}) \mathrm{D}$ for this day of the year (reference day). A positive residual indicated that a woman had a higher-than-average level at this time of the year, whereas a negative residual indicated a lower-than-average level. The projected mean was calculated by using all samples collected in the same cohort on the reference day, as well as samples taken on neighboring days, with progressively decreasing weights given to samples collected further away from the reference day. This method, therefore, seems well suited to take into account the gradual changes observed during the shoulder seasons, when levels progressively increase (spring) or decrease (fall).

Strengths of this study include its prospective design, inclusion of two cohorts with different diet and sun exposure, and large sample size. This is also the first study to include repeat blood samples on a large number of women. The repeat samples enabled us to assess temporal reproducibility and gave an indication of the potential impact of ignoring seasonal variation when studying the association of circulating vitamin $\mathrm{D}$ with disease risk. The lower ICCs observed when samples were collected in different seasons, compared with the same season, highlight the importance of taking season into account in the study design or analysis or both, as other studies have concluded [47]. The ICC of 0.63 for samples collected 8.0 to 11.7 years apart in the NSMSC compares well with the ICCs of other biomarkers that have been linked to breast cancer risk, such as post-menopausal sex hormones. However, the ICC decreased with increasing time between blood donations, although this trend did not seem to extend beyond the first 8 years. This observation underlines that a single measurement of $25(\mathrm{OH}) \mathrm{D}$ is an imperfect reflection of vitamin D status over the long time period during which breast cancer develops. Thus, the association of vitamin D status with breast cancer risk may have been underestimated because of random error in measurement of the true exposure of interest (that is, the long-term average level of $25(\mathrm{OH}) \mathrm{D})$. Another limitation of our study is the relatively small number of subjects with very high levels of circulating 25(OH)D ( $\geq 100 \mathrm{nmol} / \mathrm{L})$.

\section{Conclusions}

This large prospective study does not support a relationship between circulating $25(\mathrm{OH}) \mathrm{D}$ and risk of breast cancer, except possibly in younger women. These results add to a growing body of evidence from prospective studies and randomized trials that suggests that higher vitamin D levels do not reduce breast cancer risk. Recommendations in regard to vitamin D supplementation should be based on considerations other than breast cancer prevention, such as bone health.

\section{Abbreviations}

25(OH)D: 25-hydroxyvitamin D; BMI: body mass index; Cl: confidence interval; CV: coefficient of variation; ER: estrogen receptor; HRT: hormone replacement therapy; ICC: intraclass correlation coefficient; IGF-I: insulin-like growth factor 1; MET: metabolic equivalent of task; MSC: Mammary Screening Cohort; NSMSC: Northern Sweden Mammary Screening Cohort; NYUWHS: New York University Women's Health Study; OR: odds ratio; VDR: vitamin $\mathrm{D}$ receptor.

\section{Authors' contributions}

SS interpreted the data and drafted the manuscript. YA performed the statistical analysis and critically reviewed the manuscript. PL, AA, YC, GH, EL, PT, and RS critically reviewed the manuscript. KK conceived of the study design, interpreted the data, and critically reviewed the manuscript. $\mathrm{RH}$ performed the $25(\mathrm{OH}) \mathrm{D}$ assay and critically reviewed the manuscript. TC interpreted the data and critically reviewed the manuscript. SR performed the estrone analyses and critically reviewed the manuscript. AZ-J secured funding, conceived of the study design, interpreted the data, and drafted the manuscript. All authors read and approved the final manuscript.

\section{Competing interests}

The authors declare that they have no competing interests.

\section{Acknowledgements}

This work was supported by National Cancer Institute grants R01 CA098661 and P30 CA016087 and Center grant ES000260 from the National Institute of Environmental Health Sciences.

\section{Author details}

'Department of Population Health, New York University School of Medicine, 650 First Avenue, New York, NY 10016, USA. ²Department of Oncology, Umeå University Hospital, S-90185, Umeå, Sweden. ${ }^{3}$ New York University Cancer Institute, New York University School of Medicine, 530 First Avenue, New York, NY 10016, USA. ${ }^{4}$ Heartland Assays Inc., 2711 South Loop Drive, Suite 4400, Ames, IA 50010, USA. ${ }^{5}$ Department of Obstetrics and Gynecology, New York University School of Medicine, 550 First Avenue, New York, NY 10016, USA. 'Department of Public Health and Clinical Medicine/Nutritional Research, Umeå University, SE-901 87, Umeå, Sweden. ${ }^{7}$ Department of Medical Biosciences/Pathology, Umeå University, SE-901 85, Umeå, Sweden. ${ }^{8}$ International Agency for Research on Cancer, 150, Course Albert Thomas, 69372 Lyon Cedex 08, France. ${ }^{9}$ Radiation Effects Research Foundation, 5-2 Hijiyama Park, Minami-ku, Hiroshima, 732-0815, Japan.

Received: 28 September 2012 Revised: 18 January 2013 Accepted: 22 February 2013 Published: 26 February 2013

\section{References}

1. Welsh J: Vitamin D and breast cancer: insights from animal models. Am J Clin Nutr 2004, 80:1721S-1724S.

2. Bertone-Johnson ER: Vitamin D and breast cancer. Ann Epidemiol 2009, 19:462-467.

3. Institute of Medicine; Food and Nutrition Board: In Dietary Reference Intakes for Calcium and Vitamin D. Edited by: Ross AC, Taylor CL, Yaktine AL, Del Valle HB. Washington, DC: Institute of Medicine; Food and Nutrition Board; 2010:

4. Friedrich M, Diesing D, Cordes T, Fischer D, Becker S, Chen TC, Flanagan JN, Tangpricha V, Gherson I, Holick MF, Reichrath J: Analysis of 25hydroxyvitamin D3-1alpha-hydroxylase in normal and malignant breast tissue. Anticancer Res 2006, 26:2615-2620.

5. Davis CD: Vitamin D and cancer: current dilemmas and future research needs. Am J Clin Nutr 2008, 88:565S-569S.

6. Prentice A, Goldberg GR, Schoenmakers I: Vitamin D across the lifecycle: physiology and biomarkers. Am J Clin Nutr 2008, 88:500S-506S. 
7. Welsh J, Wietzke JA, Zinser GM, Byrne B, Smith K, Narvaez CJ: Vitamin D-3 receptor as a target for breast cancer prevention. J Nutr 2003, 133:2425S-24335.

8. Chlebowski RT, Johnson KC, Kooperberg C, Pettinger M, WactawskiWende J, Rohan T, Rossouw J, Lane D, O'Sullivan MJ, Yasmeen S, Hiatt RA, Shikany JM, Vitolins M, Khandekar J, Hubbell FA, Women's Health Initiative Investigators: Calcium plus vitamin d supplementation and the risk of breast cancer. J Natl Cancer Inst 2008, 100:1581-1591.

9. Freedman DM, Chang SC, Falk RT, Purdue MP, Huang WY, McCarty CA, Hollis BW, Graubard Bl, Berg CD, Ziegler RG: Serum levels of vitamin D metabolites and breast cancer risk in the prostate, lung, colorectal, and ovarian cancer screening trial. Cancer Epidemiol Biomarkers Prev 2008, 17:889-894.

10. McCullough ML, Stevens VL, Patel R, Jacobs EJ, Bain EB, Horst RL, Gapstur SM, Thun MJ, Calle EE: Serum 25-hydroxyvitamin D concentrations and postmenopausal breast cancer risk: a nested case control study in the Cancer Prevention Study-II Nutrition Cohort. Breast Cancer Res 2009, 11:R64.

11. Agborsangaya CB, Surcel HM, Toriola AT, Pukkala E, Parkkila S, Tuohimaa P, Lukanova A, Lehtinen M: Serum 25-hydroxyvitamin D at pregnancy and risk of breast cancer in a prospective study. Eur I Cancer 2010, 46:467-470.

12. Almquist $M$, Bondeson AG, Bondeson L, Malm J, Manjer J: Serum levels of vitamin D, PTH and calcium and breast cancer risk-a prospective nested case-control study. Int J Cancer 2010, 127:2159-2168.

13. Eliassen AH, Spiegelman D, Hollis BW, Horst RL, Willett WC, Hankinson SE: Plasma 25-hydroxyvitamin D and risk of breast cancer in the Nurses' Health Study II. Breast Cancer Res 2011, 13:R50.

14. Amir E, Cecchini RS, Ganz PA, Costantino JP, Beddows S, Hood N, Goodwin PJ: 25-Hydroxy vitamin-D, obesity, and associated variables as predictors of breast cancer risk and tamoxifen benefit in NSABP-P1. Breast Cancer Res Treat 2012, 133:1077-1088.

15. Engel P, Fagherazzi G, Boutten A, Dupre T, Mesrine S, Boutron-Ruault MC, Clavel-Chapelon F: Serum 25(OH) vitamin D and risk of breast cancer: a nested case-control study from the French E3N cohort. Cancer Epidemiol Biomarkers Prev 2010, 19:2341-2350.

16. Bertone-Johnson ER, Chen WY, Holick MF, Hollis BW, Colditz GA, Willett WC, Hankinson SE: Plasma 25-hydroxyvitamin D and 1,25-dihydroxyvitamin D and risk of breast cancer. Cancer Epidemiol Biomarkers Prev 2005, 14:1991-1997.

17. Rejnmark $L$, Tietze A, Vestergaard P, Buhl L, Lehbrink $M$, Heickendorff $L$, Mosekilde $L$ : Reduced prediagnostic 25 -hydroxyvitamin $D$ levels in women with breast cancer: a nested case-control study. Cancer Epidemiol Biomarkers Prev 2009, 18:2655-2660.

18. Chung M, Lee J, Terasawa T, Lau J, Trikalinos TA: Vitamin D with or without calcium supplementation for prevention of cancer and fractures: an updated meta-analysis for the U.S. Preventive Services Task Force. Ann Intern Med 2011, 155:827-838.

19. International Agency for Research on Cancer: Vitamin D and cancer. In IARC Working Group Reports. Volume 5. Lyon, France: International Agency for Research on Cancer; 2008:143-148.

20. Toniolo PG, Pasternack BS, Shore RE, Sonnenschein E, Koenig KL, Rosenberg C, Strax P, Strax S: Endogenous hormones and breast cancer: a prospective cohort study. Breast Cancer Res Treat 1991, 18(Suppl 1):S23-26.

21. Hallmans $G$, Agren A, Johansson $G$, Johansson A, Stegmayr B, Jansson JH, Lindahl B, Rolandsson O, Söderberg S, Nilsson M, Johansson I, Weinehall L: Cardiovascular disease and diabetes in the Northern Sweden Health and Disease Study Cohort - evaluation of risk factors and their interactions. Scand J Public Health Supp/ 2003, 61:18-24.

22. Kato I, Toniolo P, Koenig KL, Kahn A, Schymura M, Zeleniuch-Jacquotte A: Comparison of active and cancer registry-based follow-up for breast cancer in a prospective cohort study. Am J Epidemiol 1999, 149:372-378.

23. Wagner D, Hanwell HE, Vieth R: An evaluation of automated methods for measurement of serum 25-hydroxyvitamin D. Clin Biochem 2009, 42:1549-1556.

24. Zeleniuch-Jacquotte A, Shore RE, Koenig KL, Akhmedkhanov A, Afanasyeva Y, Kato I, Kim MY, Rinaldi S, Kaaks R, Toniolo P: Postmenopausal levels of oestrogen, androgen, and SHBG and breast cancer: long-term results of a prospective study. Br J Cancer 2004, 90:153-159.

25. Rinaldi S, Déchaud H, Biessy C, Morin-Raverot V, Toniolo P, ZeleniuchJacquotte A, Akhmedkhanov A, Shore RE, Secreto G, Ciampi A, Riboli E,
Kaaks R: Reliability and validity of commercially available, direct radioimmunoassays for measurement of blood androgens and estrogens in postmenopausal women. Cancer Epidemiol Biomarkers Prev 2001, 10:757-765.

26. Borkowf $C B$, Albert PS, Abnet CC: Using lowess to remove systematic trends over time in predictor variables prior to logistic regression with quantile categories. Stat Med 2003, 22:1477-1493.

27. Brock K, Huang WY, Fraser DR, Ke L, Tseng M, Stolzenberg-Solomon R, Peters U, Ahn J, Purdue M, Mason RS, McCarty C, Ziegler RG, Graubard B: Low vitamin $D$ status is associated with physical inactivity, obesity and low vitamin $D$ intake in a large US sample of healthy middle-aged men and women. J Steroid Biochem Mol Biol 2010, 121:462-466.

28. McCullough ML, Weinstein SJ, Freedman DM, Helzlsouer K, Flanders WD, Koenig K, Kolonel L, Laden F, Le Marchand L, Purdue M, Snyder K, Stevens VL, Stolzenberg-Solomon R, Virtamo J, Yang G, Yu K, Zheng W, Albanes D, Ashby J, Bertrand K, Cai H, Chen Y, Gallicchio L, Giovannucci E, Jacobs EJ, Hankinson SE, Hartge P, Hartmuller V, Harvey C, Hayes RB, et al: Correlates of circulating 25-hydroxyvitamin D: cohort consortium vitamin D pooling project of rarer cancers. Am J Epidemiol 2010, 172:21-35.

29. Winzer BM, Whiteman DC, Reeves MM, Paratz JD: Physical activity and cancer prevention: a systematic review of clinical trials. Cancer Causes Control 2011, 22:811-826.

30. van Buuren S: Multiple imputation of discrete and continuous data by fully conditional specification. Stat Methods Med Res 2007, 16:219-242.

31. Chen $P$, Hu P, Xie D, Qin Y, Wang F, Wang H: Meta-analysis of vitamin D, calcium and the prevention of breast cancer. Breast Cancer Res Treat 2010, 121:469-477.

32. Chlebowski RT: Vitamin D and breast cancer: interpreting current evidence. Breast Cancer Res 2011, 13:217.

33. Janowsky EC, Lester GE, Weinberg CR: Association between low levels of 1,25-dihydroxyvitamin D and breast cancer risk. Public Health Nutr 1999, 2:283-291.

34. Abbas S, Linseisen J, Slanger T, Kropp S, Mutschelknauss E, Flesch-Janys D, Chang-Claude J: Serum 25-hydroxyvitamin D and risk of postmenopausal breast cancer-results of a large case-control study. Carcinogenesis 2008, 29:93-99.

35. Abbas S, Chang-Claude J, Linseisen J: Plasma 25-hydroxyvitamin D and premenopausal breast cancer risk in a German case-control study. Int $J$ Cancer 2009, 124:250-255.

36. Crew KD, Gammon MD, Steck SE, Hershman DL, Cremers S, Dworakowski E, Shane E, Terry MB, Desai M, Teitelbaum SL, Neugut Al, Santella RM: Association between plasma 25 -hydroxyvitamin $\mathrm{D}$ and breast cancer risk. Cancer Prev Res (Phila) 2009, 2:598-604.

37. Lowe LC, Guy M, Mansi JL, Peckitt C, Bliss J, Wilson RG, Colston KW: Plasma 25-hydroxy vitamin $D$ concentrations, vitamin $D$ receptor genotype and breast cancer risk in a UK Caucasian population. Eur I Cancer 2005, 41:1164-1169.

38. Dorgan J, Stanczyk F, Kahle L, Brinton L: Prospective case-control study of premenopausal serum estradiol and testosterone levels and breast cancer risk. Breast Cancer Res 2010, 12:R98.

39. Fedirko V, Torres-Mejía G, Ortega-Olvera C, Biessy C, Angeles-Llerenas A, Lazcano-Ponce E, Saldaña-Quiroz VA, Romieu I: Serum 25-hydroxyvitamin $\mathrm{D}$ and risk of breast cancer: results of a large population-based casecontrol study in Mexican women. Cancer Causes Control 2012, 23:1149-1162.

40. Welsh J, Wietzke J, Zinser G, Smyczek S, Romu S, Tribble E, Welsh J, Byrne B, Narvaez C: Impact of the Vitamin D3 receptor on growth-regulatory pathways in mammary gland and breast cancer. $\int$ Steroid Biochem Mol Biol 2002, 83:85-92.

41. Zhang $X$, Giovannucci E: Calcium, vitamin D and colorectal cancer chemoprevention. Best Pract Res Clin Gastroenterol 2011, 25:485-494

42. Neuhouser ML, Manson JE, Millen A, Pettinger M, Margolis K, Jacobs ET, Shikany JM, Vitolins M, Adams-Campbell L, Liu S, LeBlanc E, Johnson KC, Wactawski-Wende J: The influence of health and lifestyle characteristics on the relation of serum 25-hydroxyvitamin D with risk of colorectal and breast cancer in postmenopausal women. Am J Epidemiol 2012, 175:673-684.

43. Millen AE, Wactawski-Wende J, Pettinger M, Melamed ML, Tylavsky FA, Liu S, Robbins J, LaCroix AZ, LeBoff MS, Jackson RD: Predictors of serum 25-hydroxyvitamin $\mathrm{D}$ concentrations among postmenopausal women: 
the Women's Health Initiative Calcium plus Vitamin D clinical trial. Am J Clin Nutr 2010, 91:1324-1335.

44. Gallicchio L, Helzlsouer KJ, Chow WH, Freedman DM, Hankinson SE,

Hartge P, Hartmuller V, Harvey C, Hayes RB, Horst RL, Koenig KL, Kolonel LN, Laden F, McCullough ML, Parisi D, Purdue MP, Shu XO, Snyder K,

Stolzenberg-Solomon RZ, Tworoger SS, Varanasi A, Virtamo J, Wilkens LR, Xiang YB, Yu K, Zeleniuch-Jacquotte A, Zheng W, Abnet CC, Albanes D, et al: Circulating 25-hydroxyvitamin $\mathrm{D}$ and the risk of rarer cancers: design and methods of the cohort consortium vitamin D pooling project of rarer cancers. Am J Epidemiol 2010, 172:10-20.

45. Lukanova A, Andersson R, Wulff M, Zeleniuch-Jacquotte A, Grankvist K,

Dossus L, Afanasyeva Y, Johansson R, Arslan AA, Lenner P, Wadell G,

Hallmans $G$, Toniolo P, Lundin E: Human chorionic gonadotropin and alpha-fetoprotein concentrations in pregnancy and maternal risk of breast cancer: a nested case-control study. Am J Epidemiol 2008, 168:1284-1291.

46. Richardson BE, Hulka BS, David Peck JL, Hughes $C L$, van den Berg BJ, Christianson RE, Calvin JA: Levels of maternal serum alpha-fetoprotein (AFP) in pregnant women and subsequent breast cancer risk. Am J Epidemiol 1998, 148:719-727.

47. Jorde R, Sneve M, Hutchinson M, Emaus N, Figenschau Y, Grimnes G: Tracking of serum 25 -hydroxyvitamin $D$ levels during 14 years in a population-based study and during 12 months in an intervention study. Am J Epidemiol 2010, 171:903-908.

doi:10.1186/bcr3390

Cite this article as: Scarmo et al:: Circulating levels of 25-hydroxyvitamin $\mathrm{D}$ and risk of breast cancer: a nested case-control study. Breast Cancer

Research 2013 15:R15.

\section{Submit your next manuscript to BioMed Central and take full advantage of:}

- Convenient online submission

- Thorough peer review

- No space constraints or color figure charges

- Immediate publication on acceptance

- Inclusion in PubMed, CAS, Scopus and Google Scholar

- Research which is freely available for redistribution

Submit your manuscript at www.biomedcentral.com/submit 